\title{
Influence of hydric solicitations on the morphological behavior of hemp
}

\section{concrete}

\author{
Fares Bennai ${ }^{a, b, c^{*}}$, Chady El Hachem ${ }^{a}$, Kamilia Abahri ${ }^{a}$, Rafik Belarbi ${ }^{b, c}$ \\ a LMT, ENS Paris-Saclay, CNRS, Université Paris Saclay, 61 Avenue du Président Wilson, 94230 Cachan, France \\ b LaSIE UMR 7356, CNRS, Université de La Rochelle, Avenue Michel Crépeau, 17042 La Rochelle Cedex 1, France \\ c 4ev Lab, EDF R\&D, CNRS, LaSIE, Université de La Rochelle, Avenue Michel Crépeau 17042 La Rochelle cedex1, France
}

Received: 12 Fabuary 2019 / Accepted: 13 June 2019 / Published online: 05 July 2019

(C) The Author(s) 2019. This article is published with open access and licensed under a Creative Commons Attribution 4.0 International License.

\begin{abstract}
The use of bio-based materials such as hemp concrete in the field of construction allows limiting environmental impacts and improving the energy performances of buildings. The aim of this paper is to understand the influence of adsorption and desorption of moisture in hemp concrete on its internal morphology and its dimensional variations. That's why, the high porosity and the adsorption capacity of hemp concrete were discussed. Then, an experimental cell was developed to follow the geometric evolution over time of hemp concrete microstructure under hydric solicitations: humidification and drying. The digital image correlation was used to determine the strains fields on the surface of the material. This technique showed the behavior of this hygroscopic material subjected to different hygrometries. Indeed, the hemp shiv undergoes larger strains than the binder, thus affecting the morphology of hemp concrete. The results obtained highlighted the influence of the hydric state of hemp concrete on its very heterogeneous microstructure. It has also been revealed that the durability of the material can be affected by the dimensional variations caused by the relative humidity variations.
\end{abstract}

Keywords: Hemp concrete; Microstructure; Digital image correlation; Adsorption; Strain

\section{Introduction}

In recent years, global demand for energy has increased and the energy consumption curve rises enormously. Between 1971 and 2016, total final consumption (TFC) more than doubled, according to the International Energy Agency (IEA) from 4244 Mtoe to 9426 Mtoe [1].

The different needs have led to the exhaustion of the energy resources and the environment pollution. These environmental and energy contexts encourage researchers to seek more and more environmentally friendly solutions. In fact, the use of bio-based materials, such as hemp concrete, allow to provide unavoidable solutions to face the requirements of sustainable development.

Hemp concrete is bio-based material composed of hemp shives and a binder mainly based on lime [2,3]. This environmentally friendly material allows the storage of carbon [4]. and it can cover several uses in buildings that differ in the formulation used [5]. Today, hemp concrete is an interesting alternative material for renovation and the construction of new buildings. Indeed, this bio-based material has excellent acoustic properties [6,7] and thermal insulation including a low thermal conductivity [8-10] which can reduce winter thermal losses and protects from summer heat waves.

On the other hand, this material has several hydric advantages, it has a high water vapor permeability $[11,12]$ and allows to regulate the humidity naturally and to moderate the relative humidity variations of the ambient air $[13,14]$. Several studies have shown that the hygrothermal properties of hemp concrete allow it to reduce daily variations in relative humidity, dampen the temperature changes and reduce energy consumption [15] while ensuring a better hygrothermal comfort of building [16].

hemp concrete is very heterogeneous and anisotropic with a complex microstructure. The binder and hemp shiv exhibit different behaviors with environmental conditions variations. In addition, physical phenomena involved at the small scales strongly influence the overall behavior of the material [17]. Although it is known that excess moisture affects the energy consumption and sustainability of buildings. In addition, as building material, hemp concrete is often in interaction with the relative humidity of air, the microscopic properties of this bio-based material change with the water content [18-20]. In

* Corresponding author: Fares Bennai, E-mail: fares.bennai1@univ-Ir.fr 
addition, the hemp shiv is a hygroscopic material and quickly absorbs large quantities of water [21]. This can cause changes in these intrinsic properties, as well as dimensional variations (swelling or shrinkage) and damage, which in some cases lead to its degradation and deterioration. It is therefore essential to evaluate the behavior of hemp concrete under hydric solicitations to better understand its degradation mechanisms.

This work proposes the study of the effect of hydric solicitations of humidifying and drying on the morphology of hemp concrete by the technique of digital image correlation (DIC). The swelling and the shrinkage of the material caused by the changes in relative humidity were also studied. For this, an original device was designed to follow the evolution of a surface of the hemp concrete sample over time. Subsequently, the numerical processing with DIC allowed to determine the strain fields in the material caused by the moisture conditions variations.

\section{Material}

Hemp shiv: The shiv used are commercial products Technichanvre (France). Their bulk density is about 110 $\mathrm{kg} / \mathrm{m}^{3}$. The dimensions of the particles are of the order of 2 to $25 \mathrm{~mm}$.

Binder: Batichanvre binder is used for making the studied hemp concrete. This binder is a mixture of: natural lime from St. Astier (Hydraulics: NHL and aerial: $\mathrm{CL}$ ), cement CEM I 52.5, and various additives to improve the rheology and permeability of hemp concrete.

Formulation: Hemp concrete has a variability of structure depending on the used formulation. In this study, the retained application is a wall application. It is developed from the professional rules of hemp concrete implementation and corresponds to a composition of materials used on construction sites. The mass dosages of shiv, lime and water are recapitulated in Table 1 with a ratio of 1.4 between the water and binder masses. The proportion between the binder and shiv masses is 2.5 [8].

Table 1. Composition of the studied material.

\begin{tabular}{ll}
\hline Hemp shiv $(\mathrm{kg})$ & 10 \\
Binder $(\mathrm{kg})$ & 25 \\
Water $(\mathrm{kg})$ & 35 \\
\hline
\end{tabular}

\section{Methods}

The objective of this study is to measure the fields of displacement and strains on the hemp concrete surface exposed to different states of hydric loading. The general principle of DIC $2 D$ is to first acquire several images for the same surface of the tested sample. Then, we search the homologous points between the reference image and the deformed image, and finally deduce the displacements field, then by derivation, the strains field.

\subsection{The principle of the digital image correlation}

Digital image correlation is a measurement technique that allows to determine the displacement fields at different levels of loading from 2D images. It can be used from the microscopic scale to the macroscopic scale. This method is used in materials to determine the strain fields and detect cracks. It can also be used in the case of porous and fibrous materials.

If the reference state is represented by a function of gray levels $f(x)$, and the deformed state is represented by the function of gray levels $g(x)$, the conservation of the gray level requires:

$$
f(x)=g(x+u(x))
$$

Where $u(x)$ is the searched displacements field. It is considered homogeneous and bilinear, its determination consists in minimizing the residue square of the correlation over the whole of the region of interest [22]:

$$
\varphi_{c}=|g(x+u(x))-f(x)|
$$

The problem to be solved is nonlinear and badly posed since there are three unknowns for a given gray level. For this, a global approach of image correlation is proposed [23], it is a question of decomposing $u(x)$ from form functions of the finite element type, imposing the continuity of the field of displacements. The displacement field is then searched in the form:

$$
u(x)=\sum_{i} u_{n} \psi_{n}(x)
$$

Where $u_{n}$ are the unknown freedom degrees associated with the form function base $\psi_{n}(x)$. The problem therefore consists in minimizing $\phi_{c}{ }^{2}$ with respect to $u_{n}$. The solution is iteratively approximated, where at each iteration $n$ the vector containing all the amplitudes $u_{n}$ is corrected by the displacement amplitudes $\{d u\}$. Finally, the linear system to solve is:

$$
[\mathrm{M}]\{\mathrm{du}\}=\{\mathrm{b}\}
$$

Where $[M]$ is the image correlation matrix given by:

$$
M_{k l}=\int_{\Omega}\left[\left(\psi_{k} \cdot \nabla f\right)(x)\left(\psi_{1} \cdot \nabla f\right)(x)\right] d x
$$

And the vector $\{b\}$ is as follows:

$$
b_{k}=\int_{\Omega}\left(f-\tilde{g}^{(n)}\right)\left(\psi_{k} \cdot \nabla f\right)(x) d x
$$

\subsection{Experimental procedure}

The test involves imposing hydric solicitations (humidification and drying) on the hemp concrete samples. Then along drying or sorption we followed the evolution of the morphology of the sample surface by taking successive images up to a given equilibrium. These images were then processed to extract the associated fields of displacements and strains.

The experimental device presented in the Fig. 1 is composed of a desiccator where the considered sample is conditioned using saline solutions, a $6.5 \mu \mathrm{m}$ resolution camera, two projectors that allow the illumination of the desiccator and 
the surface of the sample, a central data acquisition, and finally a trigger which allows the triggering of the acquisition of the signal and to control the acquisition period of the images. In addition, a balance connected to the acquisition central is placed inside the desiccator to follow the evolution of the mass of hemp concrete samples studied during the test.

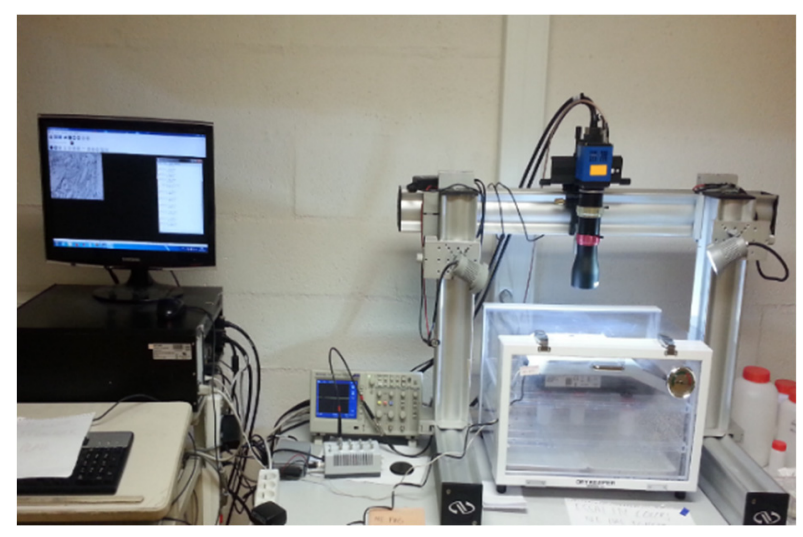

Figure 1. Developed experimental device of DIC.

The relative humidity inside the desiccator is ensured by saturated saline solutions. For the humidification condition, the sample is initially dried in an oven at $60^{\circ} \mathrm{C}$ until mass stabilized and then placed in the desiccator regulated at $76 \%$ relative humidity using Sodium Chloride $\mathrm{NaCl}$. Concerning the drying condition, the sample initially saturated is subjected to a relative humidity of $3 \%$ in the desiccator provided by the silica gel. The test room is maintained at a constant ambient temperature. The duration of the test is on average 3 days. Since the hemp shiv has a high-water adsorption capacity because of its very hygroscopic character. The period between two successive images was chosen smaller at the beginning of the test to be able to follow the strains of the first moments and facilitate the treatment of the results. The DCl software used is Correli_Q4 [23]. This software was developed at the LMT laboratory of ENS Paris-Saclay. It uses Q4 elements for the discretization of the images.

\section{Results and discussion}

The hemp concrete studied in this paper present a very porous structure. Its very high porosity accessible to water is of the order of $72.38 \%$ and the maximum water content of $148.52 \%$, This parameter provides the material with excellent hygrothermal properties. Fig. 2 shows the pore size distribution of the studied hemp concrete obtained by the mercury intrusion.

The porosity of hemp concrete is organized mainly into two categories of pore: the first corresponds to the porosity of the binder and hemp shiv, and the second corresponds to the interparticle porosity. This latter is due to the arrangement and positioning of vegetable fibers in the hemp concrete volume.

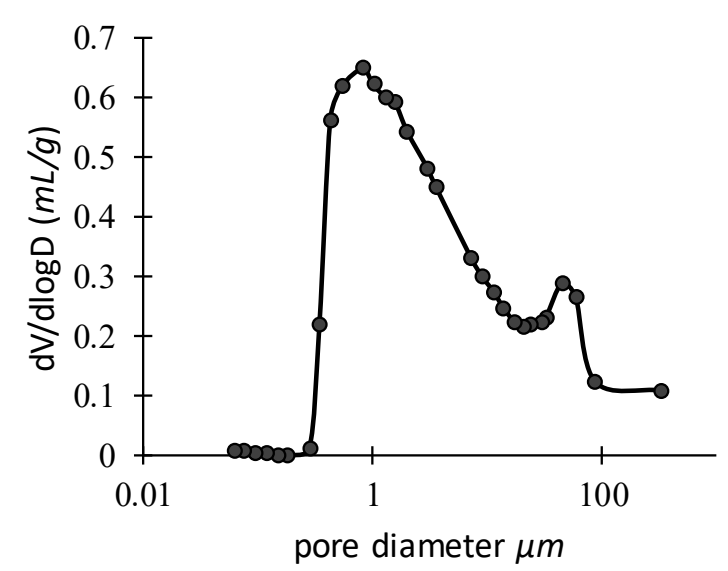

Figure 2. Pore size distributions obtained by mercury intrusion.

The high porosity of hemp concrete leads to a high-water adsorption capacity as shown by the hemp concrete sorption isothermal curve presented in Fig. 3 This figure shows that the water content increases gradually, and becomes important for high relative humidities, due to the triggering of capillary condensation mechanisms. In addition, the adsorption capacity of the water of the material is proportional to the hemp shiv dosage. For the same relative humidity, the water content at equilibrium increases with the decrease of the ratio Binder/ Hemp shiv. Finally, it is noted that the curves of sorption isotherms obtained have a hysteresis between the sorption and the desorption which extends at the lowest pressures. This phenomenon is mainly attributed to the complex morphology of the porous network of the studied material.

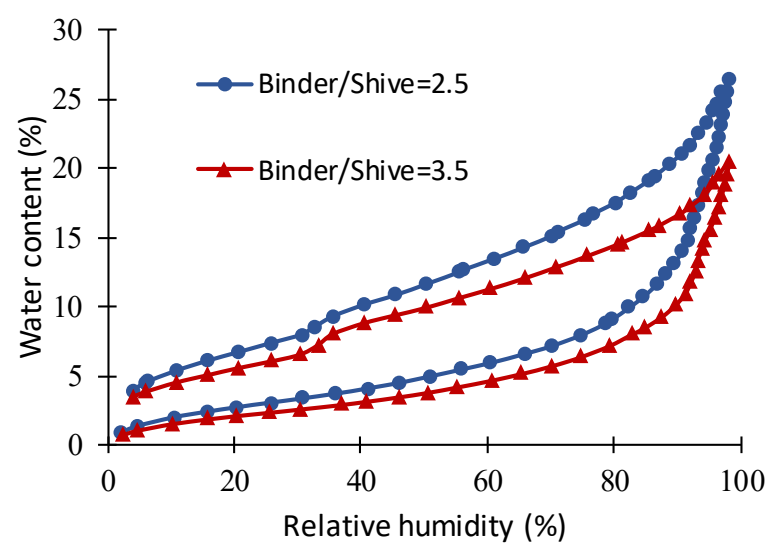

Figure 3. Adsorption and desorption isotherm curves of hemp concrete.

In the rest of this paper, we are interested in digital image correlation. The material humidification was performed by exposing the dry sample of hemp concrete to $76 \%$ of relative humidity. Fig.4a shows the reference image of the dry material. The obtained results illustrate strains fields in the $x x$ direction (Fig.4a), $y y$ (Fig.4b) and $x y$ (Fig.4c).

It can be observed that the calculated strains are anisotropic and dependent on the complex microstructure of the material. The largest observed strains are at the level of hemp 
shives and interparticle porosity. This is due to the swelling of the vegetable particles and the shrinkage of the pores between hemp shiv and binder. Fig. 4 shows that the stains of the binder are homogeneous and close to zero, because the strains under hydric solicitations of the binder are not important compared to that of the vegetable aggregates, and it undergoes only low swelling.

The red zones represent the regions with the maximum positive strains (swelling), and the blue zones represent the regions with the maximum negative strains (shrinkage). The results of DIC show the swelling of the vegetable particles which causes the volume decrease of the voids of the interparticle porosity. These effects are due to the hygroscopicity of the hemp shiv and its high-water absorption capacity. The same behavior is observed in all figures $4 b-d$, which confirm the results obtained.

Moreover, the strains in the direction $y y$ are more important than those of the direction $x x$. This is strongly dependent on the orientation of the fibers in the binder since it is the vegetable fiber that drives the swelling. In addition, the strains at the interparticle porosity are even greater than those of the plant aggregates. This part of the material is stressed in shrinkage due to the swelling of the hemp shiv which tends to close the voids between vegetable particles. Given that there is no mechanical resistance of the air, the interfaces hemp shiv/binder undergo large strains by shrinking.

Fig. 5 represents the values of the displacements in the direction $y y$ along the horizontal line located at 100 pixels from the position 0 (center of the studied sample), and that as a function of the time starting from $2 \mathrm{~h}$ to $72 \mathrm{~h}$ of humidification at $76 \%$ of relative humidity. The cut of the sample is presented below the curves drawn. This figure shows that the most important displacements along the horizontal line are marked for the hemp shiv and the interparticle air. The binder is weakly influenced by the hydric solicitation. In addition, the values of the displacements increase progressively in time because the phenomena of moisture transfer are very slow. The strains depend also on the amount of water absorbed by the material. (a)

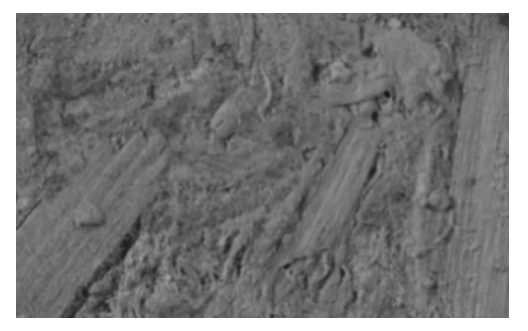

(c)

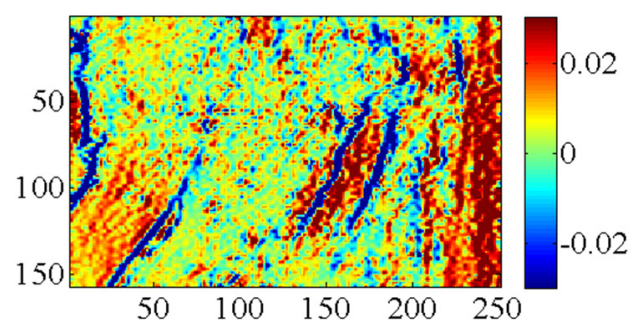

(b)

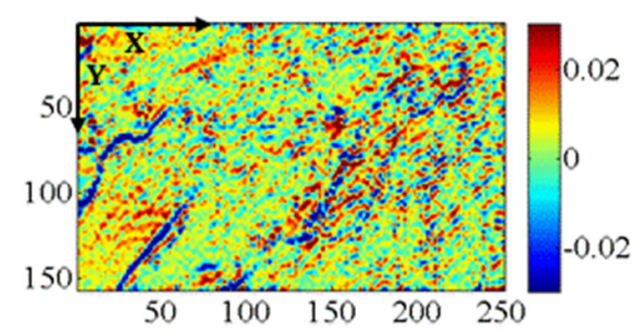

(d)

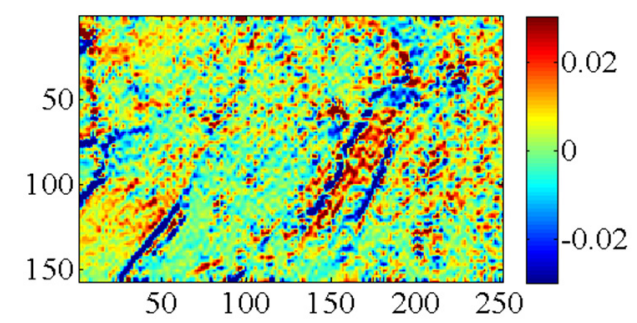

Figure 4. (a) dry state, and strains equivalent to $76 \% \mathrm{RH}$ (b) $\varepsilon_{x x}$ (c) $\varepsilon_{y y}$ and (d) $\varepsilon_{x y}$.

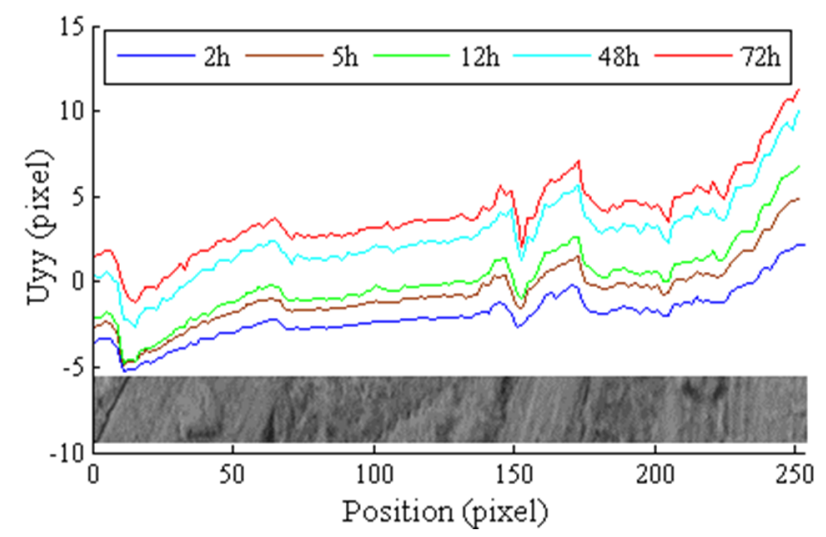

Figure 5. Displacements in the $y y$ direction as a function of time in the middle of the sample (cut to 100 pixels). 
Concerning the results of the drying of the hemp concrete sample, Fig.6a shows the reference image of the saturated material. The strains fields in the directions $x x, y y$ and $x y$ are presented in figures $6 \mathrm{~b}-\mathrm{d}$ respectively. The strains fields on the sample surface show that the exposure of the saturated hemp concrete to a very low relative humidity leads to an exchange of moisture between the sample and the desiccator enclosure. This causes the mass decrease of the sample due to the desorption of humidity. The hemp shiv releases the large quantities of absorbed water, which leads to a change in the volume of the vegetable particles that shrink (blue areas in the figures). As a result, the interparticle voids are expanded and their size increases further (red areas in the figures). Moreover, the zones of the binder mark very weak strains. Concerning the strains magnitude, it is evident that it varies along each direction of the sample. From a saturated state to a relative humidity of $3 \%$, the hemp shiv presents a shrinkage of around $0.15(15 \%)$ whereas the interparticle porosity presents a swelling of around 0.15 (15\%). These strains are more important than those of the humidification case at $76 \%$ of relative humidity because the material begins to absorb large amount of water from a relative humidity of $85 \%$ as it is shown on the sorption isotherm curve of the material (Fig.3). Construction materials are often exposed to daily variations in relative humidity, which leads to cycles of swelling / shrinkage of the internal morphology of the hemp concrete. In the long term these dimensional variations can lead to the appearance of cracks and the degradation of the material and consequently its durability will be affected [18].

(a)

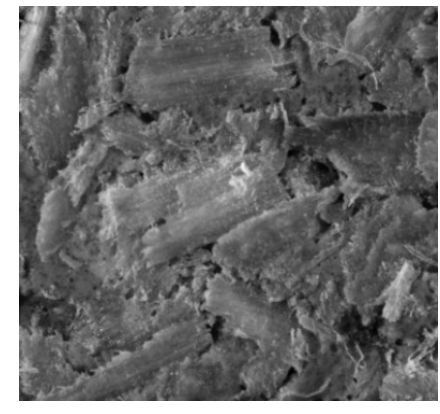

(c)

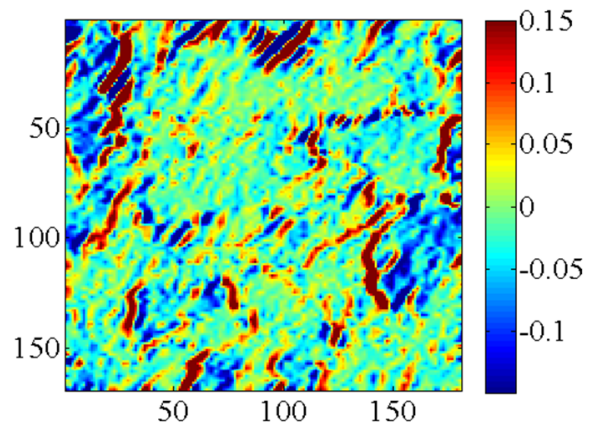

\section{Conclusions}

This study was dedicated to the characterization of the 2D hygromorphic behavior of hemp concrete to better understand the swelling and shrinkage of the material due to variations in its hydric status. The results show that hemp concrete is very porous material. This porosity is organized in intraparticle porosity in the binder and the hemp shiv and the interparticle porosity related to the arrangements of vegetable fibers. In addition, this material absorbs a large quantity of water and is very sensitive to variations in ambient relative humidity.

The digital image correlation was used to quantify and analyze the strains fields at the hemp concrete sample surface under hydric solicitations of humidification or drying. For this purpose, an original device consisting of a desiccator controlled in hygrometry and equipped with very high precision cameras has been elaborated to follow the evolution of the material morphology. It has been reported that hemp shives have significant strains compared to the binder. Humidification of the material leads to swelling of the vegetable particles and decrease of the porosity present between the binder and the hemp shiv. In addition, hydric drying causes shrinkage of vegetable aggregates and the dilation of interparticle porosity. This study highlighted the dimensional and morphological variations of hemp concrete under hydric solicitation that can affect the durability of the material and lead to its degradation.

(b)

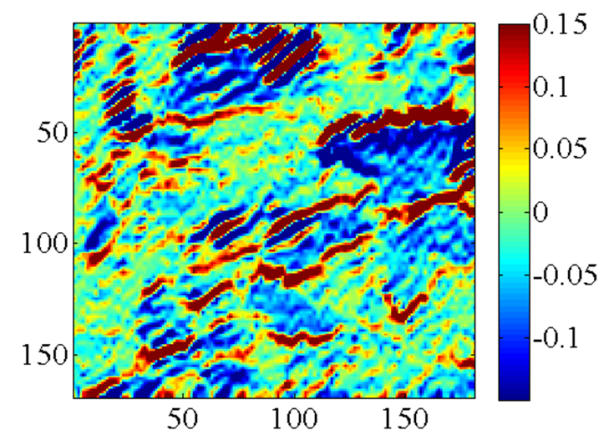

(d)

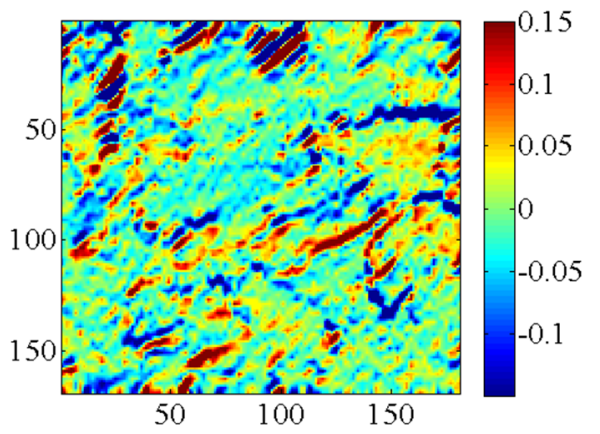

Figure 6. (a) saturated state and strains equivalent to $3 \% \mathrm{RH}$ (b) $\varepsilon_{x x}$ (c) $\varepsilon_{y y}$ and (d) $\varepsilon_{x y}$. 


\section{Acknowledgements}

The Region and the European Union support the project <CPER BATIMENT DURABLE. Axis 2 MADUR Project: Highperformance building materials with low environmental impact, sustainable and resilient> within the framework of the "Operational Program FEDER/FSE 2014-2020».

\section{References}

[1] International Energy Agency, Key Word Energy Trends. Excerpt from : World energy balances, (2016).

[2] F. Collet, J. Chamoin, S. Pretot, C. Lanos, Comparison of the hygric behaviour of three hemp concretes. Energ Buildings (2013) 62: 294303. https://doi.org/10.1016/j.enbuild.2013.03.010

[3] S. Amziane, L. Arnaud, eds., Bio-aggregate-based building materials: applications to hemp concretes, ISTE, London, 2013. https://doi.org/10.1002/9781118576809

[4] S. Amziane, F. Collet, eds., Bio-aggregates Based Building Materials, Springer Netherlands, Dordrecht, 2017. https://doi.org/10.1007/978-94-024-1031-0

[5] R. Walker, S. Pavia, R. Mitchell, Mechanical properties and durability of hemp-lime concretes. Constr Build Mater (2014) 61: 340-348. https://doi.org/10.1016/i.conbuildmat.2014.02.065

[6] M. Degrave-Lemeurs, P. Glé, A. Hellouin de Menibus, Acoustical properties of hemp concretes for buildings thermal insulation: Application to clay and lime binders. Constr Build Mater (2018) 160: 462-474. https://doi.org/10.1016/i.conbuildmat.2017.11.064

[7] P. Glé, E. Gourdon, L. Arnaud, Modelling of the acoustical properties of hemp particles. Constr Build Mater (2012) 37: 801-811. https://doi.org/10.1016/j.conbuildmat.2012.06.008

[8] F. Bennai, N. Issaadi, K. Abahri, R. Belarbi, A. Tahakourt, Experimental characterization of thermal and hygric properties of hemp concrete with consideration of the material age evolution. Heat Mass Transfer (2018) 54: 1189-1197. https://doi.org/10.1007/s00231-017-2221-2

[9] F. Collet, S. Pretot, Thermal conductivity of hemp concretes: Variation with formulation, density and water content. Constr Build Mater (2014) 65: 612-619. https://doi.org/10.1016/i.conbuildmat.2014.05.039

[10] A.D. Tran-Le, S.-T. Nguyen, T. Langlet, A novel anisotropic analytical model for effective thermal conductivity tensor of dry lime-hemp concrete with preferred spatial distributions. Energ Buildings (2019) 182: $75-87$ https://doi.org/10.1016/i.enbuild.2018.09.043

[11] M. Rahim, O. Douzane, A.D. Tran Le, G. Promis, B. Laidoudi, A. Crigny, B. Dupre, T. Langlet, Characterization of flax lime and hemp lime concretes: Hygric properties and moisture buffer capacity. Energ Buildings (2015) 88: 91-99. https://doi.org/10.1016/j.enbuild.2014.11.043

[12] F. Collet, S. Pretot, Experimental highlight of hygrothermal phenomena in hemp concrete wall. Build Environ (2014) 82: 459466. https://doi.org/10.1016/i.buildenv.2014.09.018

[13] F. Collet, S. Pretot, Experimental investigation of moisture buffering capacity of sprayed hemp concrete. Constr Build Mater (2012) 36: 5865. https://doi.org/10.1016/j.conbuildmat.2012.04.139

[14] M. Rahim, O. Douzane, A.D. Tran Le, G. Promis, T. Langlet, Characterization and comparison of hygric properties of rape straw concrete and hemp concrete. Constr Build Mater (2016) 102: 679687. https://doi.org/10.1016/j.conbuildmat.2015.11.021

[15] A. D. Tran Le, C. Maalouf, T.H. Mai, E. Wurtz, F. Collet, Transient hygrothermal behaviour of a hemp concrete building envelope. Energ Buildings (2010) 42: 1797-1806. https://doi.org/10.1016/j.enbuild.2010.05.016

[16] A. Shea, M. Lawrence, P. Walker, Hygrothermal performance of an experimental hemp-lime building. Constr Build Mater (2012) 36: 270275. https://doi.org/10.1016/j.conbuildmat.2012.04.123

[17] F. Bennai, K. Abahri, R. Belarbi, A. Tahakourt, Periodic homogenization for heat, air, and moisture transfer of porous building materials. Numer Heat Tr B-Fund (2016) 70: 420-440. https://doi.org/10.1080/10407790.2016.1230393

[18] F. Bennai, C. El Hachem, K. Abahri, R. Belarbi, Microscopic hydric characterization of hemp concrete by $\mathrm{X}$-ray microtomography and digital volume correlation. Constr Build Mater (2018) 188: 983-994. https://doi.org/10.1016/j.conbuildmat.2018.08.198
[19] R. Belarbi, F. Bennai, M.Y. Ferroukhi, C. El Hachem, K. Abahri, Multiscale modelling for better hygrothermal prediction of porous building materials. MATEC Web of Conferences (2018) 149: 02005. https://doi.org/10.1051/matecconf/201814902005

[20] K. Abahri, C. EL Hachem, F. Bennai, T. Ngoc, R. Belarbi, Prediction of Hemp Concrete Morphological Deformation by X-ray Tomography, American Concrete Institute. ACI Special Publication (2017) 320: 616625.

[21] M. Fourmentin, P. Faure, P. Pelupessy, V. Sarou-Kanian, U. Peter, D. Lesueur, S. Rodts, D. Daviller, P. Coussot, NMR and MRI observation of water absorption/uptake in hemp shives used for hemp concrete. Constr Build Mater (2016) 124: 405-413. https://doi.org/10.1016/i.conbuildmat.2016.07.100

[22] F. Hild, S. Roux, Comparison of Local and Global Approaches to Digital Image Correlation. Exp Mech (2012) 52: 1503-1519. https://doi.org/10.1007/s11340-012-9603-7

[23] G. Besnard, F. Hild, S. Roux, "Finite-Element" Displacement Fields Analysis from Digital Images: Application to Portevin-Le Châtelier Bands. Exp Mech (2006) 46: 789-803. https://doi.org/10.1007/s11340-006-9824-8 